\title{
New bioactive metabolites from the elicited marine sponge-derived bacterium Actinokineospora spheciospongiae sp. nov.
}

\author{
Ahmed Tawfike ${ }^{1,2}$, Eman Zekry Attia ${ }^{3}$, Samar Yehia Desoukey ${ }^{3}$, Dina Hajjar ${ }^{4}$, Arwa A. Makki ${ }^{4}$, Peter J. Schupp ${ }^{5^{*}}$, \\ RuAngelie Edrada-Ebel ${ }^{1}$ and Usama Ramadan Abdelmohsen ${ }^{3^{*}}$
}

\begin{abstract}
Several approaches have been dedicated to activate the cryptic gene clusters in the genomes of actinomycetes for the targeted discovery of new fascinating biomedical lead structures. In the current study, N-acetylglucosamine was used to maximize the chemical diversity of sponge-derived actinomycete Actinokineospora spheciospongiae sp. nov. HR-ESI-MS was employed for dereplication study and orthogonal partial least square-discriminant analysis was applied to evaluate the HR-ESI-MS data of the different fractions. As a result, two new fridamycins $\mathrm{H}(\mathbf{1})$ and I (2), along with three known compounds actinosporin C (3), D (4), and G (5) were isolated from the solid culture of sponge-associated actinomycete Actinokineospora spheciospongiae sp. nov., elicited with $\mathrm{N}$-acetylglucosamine. Characterization of the isolated compounds was pursued using mass spectrometry and NMR spectral data. Fridamycin $\mathrm{H}$ (1) exhibited significant growth inhibitory activity towards Trypanosoma brucei strain TC221. These results highlight the potential of elicitation in sponge-associated actinomycetes as an effective strategy for the discovery of new antiinfective natural products.
\end{abstract}

Keywords: Sponges, Actinomycetes, Actinokineospora, Fridamycin, Elicitation, Antitrypanosomal

\section{Introduction}

Marine sponge-derived actinomycetes have been recognized as potential producers of fascinating chemical scaffolds such as polyketides, alkaloids, peptides, sterols, terpenes and fatty acids (Abdelmohsen et al. 2014a, c; Genilloud 2017; Ibrahim et al. 2018; Van der Meij et al. 2017) with diverse pharmacological activities such as antichlamydial, antioxidant, antibacterial, antitrypanosomal, cytotoxic, and antibiofilm (Abdelmohsen et al. 2017; Balasubramanian et al. 2017; Cheng et al. 2015, 2017). The strain Actinokineospora spheciospongiae was first isolated by Abdelmohsen et al. in 2010 from the Red

\footnotetext{
*Correspondence: peter.Schupp@uni-oldenburg.de;

usama.ramadan@mu.edu.eg

${ }^{3}$ Department of Pharmacognosy, Faculty of Pharmacy, Minia University, Minia 61519, Egypt

${ }^{5}$ Carl-von-Ossietzky University Oldenburg, Institute for Chemistry and Biology of the Marine Environment, Postfach 2503, 26111 Oldenburg, Germany

Full list of author information is available at the end of the article
}

Sea sponge Spheciospongia vagabunda that was collected from Ras Mohamed, Egypt (Abdelmohsen et al. 2010). The strain was then described by Kampfer et al. in 2015 and the draft genome sequence was analysed (Harjes et al. 2014; Kampfer et al. 2015). The chemical and biological investigation of this strain emphasized the diversity of its natural components and resulted in identification of several new natural products (Abdelmohsen et al. 2014b; Dashti et al. 2017). Actinomycetes have been found to have the major fraction of their secondary metabolites to be transcriptionally inactive or "silent" under normal laboratory conditions (Abdelmohsen et al. 2015; Dinesh et al. 2017; Horn et al. 2015; Letzel et al. 2017; Seyedsayamdost 2014). In a study by Letzel et al. (2017), analysis of genome sequences of 119 marine actinomycetes reveals extraordinary biosynthetic diversity. Several experimental approaches have been applied to activate and identify the products of those cryptic genes using biological, chemical and genetic elicitations (Abdelmohsen et al. 2015; Dashti et al. 2017; Pettit 2011). In our previous 
work, Actinokineospora spheciospongiae broth culture was elicited with $\mathrm{N}$-acetyl glucosamine (GlcNAc) and the metabolic profile was investigated using ${ }^{1} \mathrm{H}$ NMR fingerprint methodology which resulted in identification of four new actinosporins (E-H) (Dashti et al. 2017). In the present study, the solid culture of Actinokineospora spheciospongiae sp. nov. was elicited with GlcNAc that led to the identification of two new fridamycins (1 and $\mathbf{2})$, along with three known compounds actinosporin C (3), D (4), and $\mathrm{G}(5)$. Moreover, the antitrypanosomal activity of all isolated pure compounds was also investigated.

\section{Materials and methods}

\section{Microbial fermentation, extract preparation} and compounds isolation

Actinokineospora spheciospongiae sp. nov. (DSM 45935T, GeneBank accession no. GU318361) was isolated from the Red Sea sponge Spheciospongia vagabunda that was collected by SCUBA diving from offshore Ras Mohamed, Egypt (GPS: $27^{\circ} 47.655 \mathrm{~N} ; 34^{\circ} 12.904 \mathrm{~W}$ ) in August 2006. Two hundred ISP2 agar plates (square $120 \times 120 \mathrm{~mm}$ ), each inoculated with $100 \mu \mathrm{L}$ of a 5 day old liquid culture of Actinokineospora spheciospongiae and incubated at $30{ }^{\circ} \mathrm{C}$ for $6 \mathrm{~h}$. The agar plates were then elicited with GlcNAc $(50 \mu \mathrm{L} /$ plate of a $50 \mu \mathrm{M}$ solution, Sigma-Aldrich, Darmstadt, Germany). The plates were then incubated at $30{ }^{\circ} \mathrm{C}$ for 7 days. The agar medium with bacterial biomass was cut into small pieces and transferred to $1 \mathrm{~L}$ Erlenmeyer flasks. One liter of EtOAc/flask was added to submerge the agar pieces and macerate the medium culture under shaking at $150 \mathrm{rpm}$ for overnight. The macerated medium was subsequently filtered using filter paper (A. Hartenstein, Wurzburg, Germany). The filtrates were combined and evaporated in a rotary evaporator under vacuum (Büchi, Essen, Germany) to yield $850 \mathrm{mg}$ of dried crude EtOAc extract, which was fractionated on a Sephadex LH20 (50 g, 32-64 $\mu \mathrm{m}, 100 \times 10 \mathrm{~mm}$, Merck, Darmstadt, Germany) column eluting with $\mathrm{H}_{2} \mathrm{O}$ / $\mathrm{MeOH}(90: 10 \%)$ to $100 \%$ methanol, to yield 12 fractions (50 mL each). The highly active fractions (3 and 5) were further purified by semi-preparative HPLC (Agilent, Waldbronn, Germany) using $\mathrm{H}_{2} \mathrm{O}$ /acetonitrile (95:5\%) initially for $5 \mathrm{~min}$, followed by a linear gradient to $100 \%$ acetonitrile within $40 \mathrm{~min}$ and maintained isocratically for further $5 \mathrm{~min}$. Separation was achieved on a preparative C18 column $(5 \mu \mathrm{m}, 10 \times 250 \mathrm{~mm}$, Waters XBridge, Eschborn, Germany), with a flow rate of $3.0 \mathrm{~mL} / \mathrm{min}$ yielding compounds $1(1.6 \mathrm{mg})$ and $2(1.8 \mathrm{mg})$ from fraction 3 and compounds 3-5 (2.3, 2.5 and $3 \mathrm{mg}$, respectively) from fraction 5 .

\section{LC-MS analysis}

One milligram of dried microbial extracts and/or fractions was dissolved in HPLC-grade $\mathrm{MeOH}$ to a final concentration of $1 \mathrm{mg} / \mathrm{mL}$ and subjected to high resolution LC-ESI-MS using Thermo Scientific Exact mass analysers (Thermo Scientific, Karlsruhe, Germany) coupled to a Dionex UltiMate 3000 HPLC system. The samples were eluted through a C-18 column (ACE, Mainz, Germany) with a length of $75 \mathrm{~mm}$, internal diameter of $3.0 \mathrm{~mm}$ and particle size $5 \mu \mathrm{m}$. The mobile phase consisted of $0.1 \%$ formic acid in HPLC-grade water (solvent A) and acetonitrile (solvent B). The flow rate was set at $300 \mu \mathrm{L} /$ min. Gradient elution was initiated with $10 \%$ B for 5 min, which was increased to $100 \%$ B over $30 \mathrm{~min}$, which was maintained for another 5 min before decreasing to $10 \% \mathrm{~B}$ in the next min. The column was then equilibrated with $10 \% \mathrm{~B}$ for $4 \mathrm{~min}$ until the end of the run. MS/MS was measured using LTQ Orbitrap Thermo scientific mass analysers (Thermo Scientific, Karlsruhe, Germany).

\section{Biological activity of the isolated compounds Antitrypanosomal activity}

Antitrypanosomal action had been investigated following the method reported by Abdelmohsen et al. (2014b). In brief, Complete Baltz Medium was used for cultivation of 104 trypanosomes per $\mathrm{mL}$ of the Trypanosoma brucei strain TC 221 (Missionsärztliche Klinik, University of Wurzburg). 96-well plate chambers were used for testing Trypanosomes versus various concentrations of examined compounds at $0.25-40 \mu \mathrm{M}$ in DMSO (1\%) to a final volume of $200 \mu \mathrm{L}$. For controls, DMSO (1\%) plus parasites without any examined compound were used concurrently in each plate. After that, the plates were incubated in an atmosphere of $\mathrm{CO}_{2} 5 \%$ at $37{ }^{\circ} \mathrm{C}$ for $24 \mathrm{~h}$. Then, 20 $\mu \mathrm{L}$ of Alamar Blue was added in each plate and the activity was measured by light absorption at $\Lambda 550 \mathrm{~nm}$ with a reference wavelength of $650 \mathrm{~nm}$ using an MR 700 Microplate Reader (Dynatech Engineering Ltd., Willenhall, UK) after 48 and $72 \mathrm{~h}$. The quantification of the $\mathrm{IC}_{50}$ values of the examined compounds were processed by linear interpolation in triplicate.

\section{Cytotoxicity activity}

Macrophages (J774.1) (Missionsärztliche Klinik, University of Wurzburg) were cultivated in Complete Baltz Medium free from phenol red. Different concentrations of tested compounds $(0.25-200 \mu \mathrm{M})$ at a cell density of $1 \times 10^{5}$ cells $/ \mathrm{mL}$ at $37{ }^{\circ} \mathrm{C}, 5 \% \mathrm{CO}_{2}$, and $95 \%$ humidity for $24 \mathrm{~h}$, were used for investigation of their cytotoxic properties against Macrophages (J774.1). After adding of Alamar Blue $(20 \mu \mathrm{L})$, the plates were incubated and the 
then, determination of the optical densities at $\kappa 540 \mathrm{~nm}$ and a reference wavelength of $630 \mathrm{~nm}$ were done after 48 and $72 \mathrm{~h}$, in the same way as described for the anti-trypansomal activity (Abdelmohsen et al. 2014b).

\section{Compounds characterization}

Fridamycin $\mathrm{H}(\mathbf{1})$ : Orange powder; $[\alpha]_{\mathrm{D}}^{25}+12^{\circ}(c) 1.5$, $\mathrm{MeOH}) ; \mathrm{UV}(\mathrm{MeOH}) \lambda \max (\log \varepsilon) 231$ (4.45), 253 (4.51), $293(4.37) \mathrm{nm}$; IR (KBr) ${ }_{\text {max }} 3420,2962,1710,1436,1340$, 1275, $1065 \mathrm{~cm}^{-1} ;{ }^{1} \mathrm{H}$ NMR (DMSO-d ${ }_{6}, 600 \mathrm{MHz}$ ) and ${ }^{13} \mathrm{C}$ NMR (DMSO-d $\mathrm{d}_{6}, 150 \mathrm{MHz}$ ) data, see Table 2; HR-

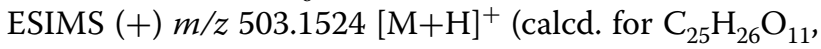
503.1553).

Fridamycin I (2): Yellow powder; $[\alpha]_{\mathrm{D}}^{25}+25^{\circ}$ (c 1.5, $\mathrm{MeOH}) ; \mathrm{UV}(\mathrm{MeOH}) \lambda \max (\log \varepsilon) 232$ (4.54), 253 (4.53), 294 (4.17) nm; IR (KBr) ${ }_{v \max } 3419,3030,1700,1650,1432$, 1345, 1275, $1065 \mathrm{~cm}^{-1}$; ${ }^{1} \mathrm{H}$ NMR (DMSO-d ${ }_{6}, 600 \mathrm{MHz}$ ) and ${ }^{13} \mathrm{C}$ NMR (DMSO- $\mathrm{d}_{6}, 150 \mathrm{MHz}$ ) data, see Table 3; HR-ESIMS (+) $m / z$ 614.2036 $[\mathrm{M}+\mathrm{Na}]^{+}$(calcd. for $\left.\mathrm{C}_{32} \mathrm{H}_{33} \mathrm{NO}_{10} \mathrm{Na}, 614.2021\right)$.

\section{Results}

Bioactivity-guided assay and metabolomic analysis

All fractions were subjected to HPLC-HR-ESIMS analysis on both negative and positive ionization switch modes to cover the maximum number of metabolites. The MS dataset was processed and data were extracted using MZmine 2.20 based on the established parameters (Tawfike et al. 2017). The dereplication study of the active fractions against DNP database revealed the presence of known metabolites, but mostly unknown hits dominated as shown in Table 1. Metabolites at $\mathrm{m} / \mathrm{z}$ (retention time in minutes) $387.0865(6.65)[\mathrm{M}-\mathrm{H}]^{-}$and 401.1025 (10.44) $[\mathrm{M}-\mathrm{H}]^{-}$, were dereplicated as $\mathrm{G}-2 \mathrm{~N}$ $\left(\mathrm{C}_{23} \mathrm{H}_{16} \mathrm{O}_{6}\right)$, an antibiotic formerly reported from actinomycete Frankia sp.(Nancy and Mary 1984), and saptomycin $\mathrm{F}\left(\mathrm{C}_{24} \mathrm{H}_{18} \mathrm{O}_{6}\right)$, an antibiotic previously isolated from Streptomyces sp.(Abe et al. 1993), respectively. The aforementioned dereplicated metabolites, depicted in Fig. 1, possessed the naphthacene-dione moiety. Additionally, the mass ion peak at $m / z 227.175[\mathrm{M}+\mathrm{H}]^{+}$for the predicted molecular formula $\mathrm{C}_{12} \mathrm{H}_{22} \mathrm{~N}_{2} \mathrm{O}_{2}$ was dereplicated as isoleucyl isoleucine anhydride. The latter is a dipeptide previously reported from Ustilago cynodontis and Beauveria bassiana (Geraci et al. 2000).

The dereplication results highlighted the previously reported active compounds that would guide the structure elucidation of the isolated unknown metabolites. Multivariate data analysis (MVDA) was performed for the MS dataset of active versus inactive fractions to pinpoint the putatively active metabolites in the antitrypanosomally-active fractions prior to any further purification attempts.

To achieve the best discrimination between the active and inactive fractions, a supervised orthogonal partial least square discriminant analysis (OPLS-DA) was carried out. The OPLS-DA scores plot (Fig. 2a) showed a significant discrimination between active and inactive fractions revealing a regression fit of $99 \%\left(R^{2}=0.99\right)$ and high predictive ability of $\mathrm{Q}^{2}=0.96$. The current OPLSDA model produced the highest predictive power $\left(\mathrm{Q}^{2}\right)$

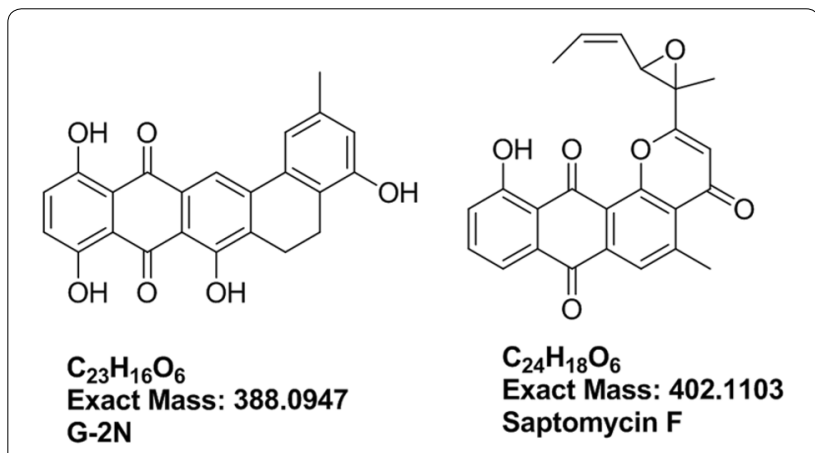

Fig. 1 Dereplicated structures from the active fractions: $G-2 N$ and saptomycin F

Table 1 The dereplication results of the active fractions against DNP database

\begin{tabular}{lcclll}
\hline Polarity & $\mathbf{m} / \mathbf{z}$ & Rt & Formula & Name & Source \\
\hline$[\mathrm{M}-\mathrm{H}]^{-}$ & 387.0865 & 6.65 & $\mathrm{C}_{23} \mathrm{H}_{16} \mathrm{O}_{6}$ & G-2N & Unknown \\
{$[\mathrm{M}+\mathrm{H}]^{+}$} & 188.1279 & 7.69 & $\mathrm{C}_{9} \mathrm{H}_{17} \mathrm{NO}_{3}$ & Unkia sp. ANP 190107 \\
{$[\mathrm{M}-\mathrm{H}]^{-}$} & 343.0952 & 8.67 & $\mathrm{C}_{18} \mathrm{H}_{12} \mathrm{~N}_{6} \mathrm{O}_{2}$ & Unknown & - \\
{$[\mathrm{M}+\mathrm{H}]^{+}$} & 227.1753 & 9.00 & $\mathrm{C}_{12} \mathrm{H}_{22} \mathrm{~N}_{2} \mathrm{O}_{2}$ & Isoleucyl isoleucine anhydride & - \\
{$[\mathrm{M}-\mathrm{H}]^{-}$} & 369.0751 & 9.84 & $\mathrm{C}_{19} \mathrm{H}_{10} \mathrm{~N}_{6} \mathrm{O}_{3}$ & Unknown & Ustilago cynodontis, Beauveria bassiana \\
{$[\mathrm{M}-\mathrm{H}]^{-}$} & 1003.325 & 9.86 & - & Complex of 501.1586 and 501.1586 m/z & - \\
{$[\mathrm{M}-\mathrm{H}]^{-}$} & 501.1586 & 9.86 & $\mathrm{C}_{31} \mathrm{H}_{18} \mathrm{~N}_{8}$ & Unknown & - \\
{$[\mathrm{M}+\mathrm{H}]^{+}$} & 357.097 & 9.88 & $\mathrm{C}_{19} \mathrm{H}_{16} \mathrm{O}_{7}$ & Fridamycin E & Streptomyces parvulus Tu 1989 \\
{$[\mathrm{M}-\mathrm{H}]^{-}$} & 401.1025 & 10.44 & $\mathrm{C}_{24} \mathrm{H}_{18} \mathrm{O}_{6}$ & Saptomycin-F & Streptomyces strain HP530 \\
{$[\mathrm{M}+\mathrm{H}]^{+}$} & 357.0968 & 15.66 & $\mathrm{C}_{16} \mathrm{H}_{8} \mathrm{~N}_{10} \mathrm{O}$ & Unknown \\
{$[\mathrm{M}-\mathrm{H}]^{-}$} & 355.0954 & 15.67 & $\mathrm{C}_{19} \mathrm{H}_{12} \mathrm{~N}_{6} \mathrm{O}_{2}$ & Unknown & - \\
\hline & & & &
\end{tabular}


when assessed by cross validation. Moreover, the statistical significance of estimated predictive power of the respective model was tested by permutation test which exhibited $Q^{2} Y$ intercept at -0.81 that indicated a valid model. A particularly useful tool that compares the variable magnitude against its reliability is the S-loadings plot obtained from the OPLS-DA model and represented in Fig. 2b, where axes plotted from the predictive component are the covariance $\mathrm{p}[1]$ against the correlation $\mathrm{p}$ (cor) [1]. The S-loadings plot highlighted the metabolites distinct for the active fractions that highly correlated to their bioactivity.
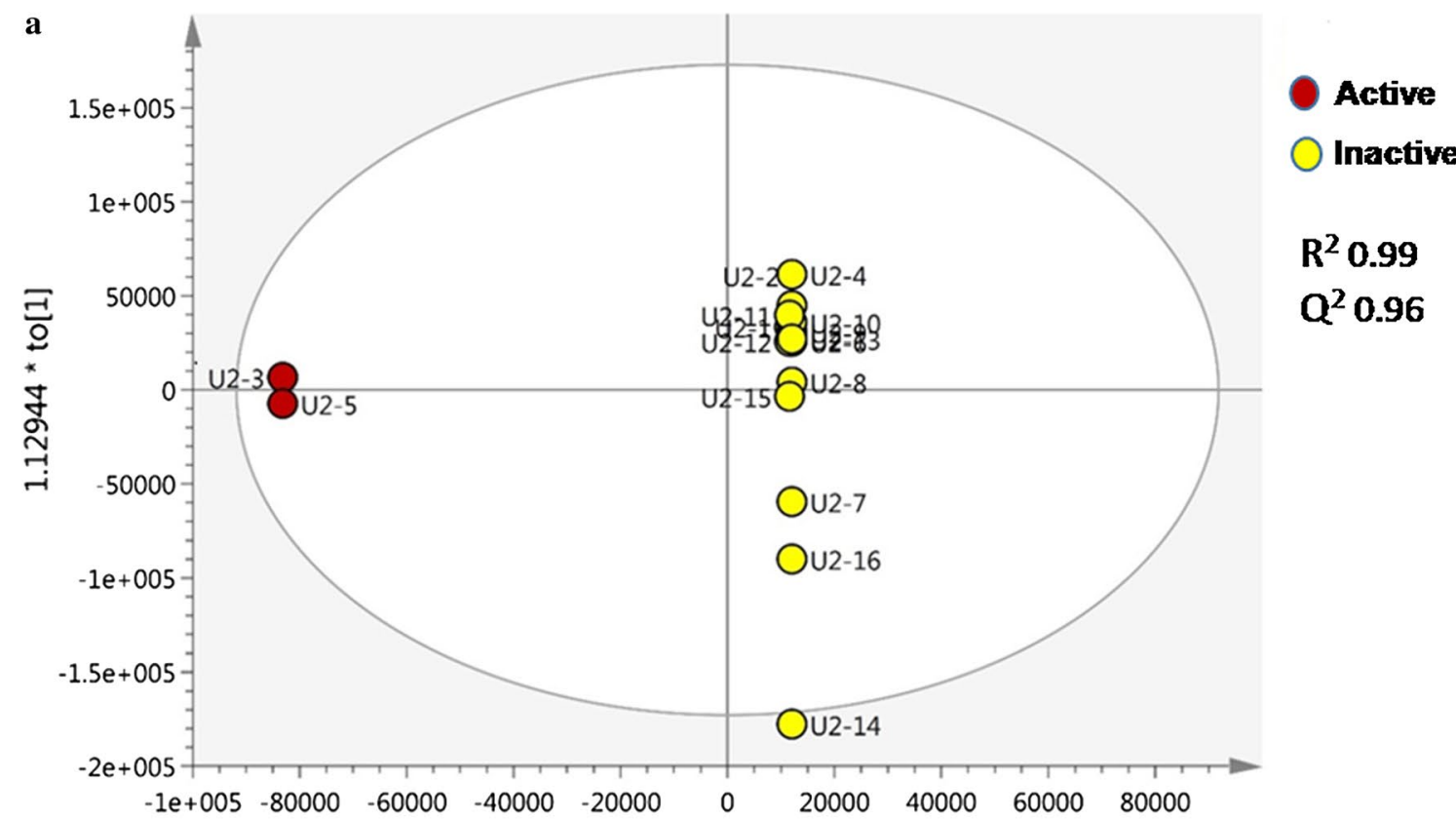

b

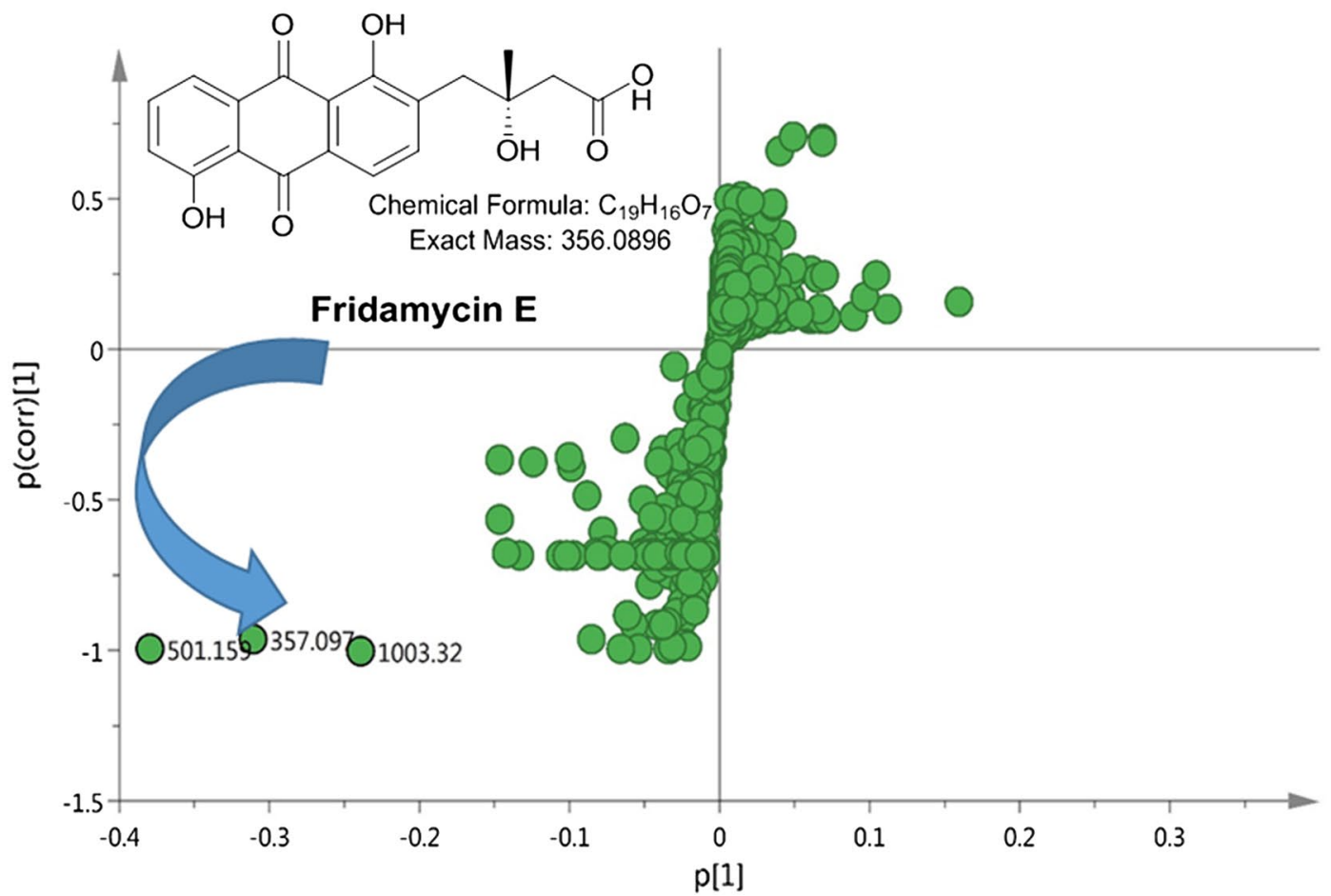

Fig. 2 a OPLS-DA score plot of active (red circle) versus inactive fractions (yellow circle). b S-loading plot showing the putatively active metabolites 
The metabolite at $\mathrm{m} / z \quad 501.159$ (Rt=9.86 $\mathrm{min}$ ) $[\mathrm{M}-\mathrm{H}]^{-}$, equivalent to $\mathrm{C}_{25} \mathrm{H}_{26} \mathrm{O}_{11}$ did not match any compounds reported in the DNP database while the $\mathrm{m} / z$ ion at $357.097(\mathrm{Rt}=9.88 \mathrm{~min})[\mathrm{M}+\mathrm{H}]^{+}$for the predicted molecular formula $\mathrm{C}_{19} \mathrm{H}_{16} \mathrm{O}_{7}$ was dereplicated for fridamycin $\mathrm{E}$, the simplest member of the angucycline family of antibiotics that was previously isolated from a mutant of Streptomyces parvulus (strain Tu 1989) (Krohn and Baltus 1988; Kunzel et al. 1999). The metabolomics and dereplication results (Table 1, Fig. 1) revealed previously undescribed putatively active metabolites that motivated us to further purify the fractions and identify the active compounds via ${ }^{1} \mathrm{D},{ }^{2} \mathrm{D}$-NMR and HR-ESIMS.

\section{Structure elucidation of the new isolated compounds}

Separation of fraction 3 delivered two hydroxyquinones with similar UV spectra $(231,253,293 \mathrm{~nm})$ indicating similar chromophores. A molecular formula of $\mathrm{C}_{25} \mathrm{H}_{26} \mathrm{O}_{11}$ was established for 1 (Fig. 3) by positive HR-ESIMS analysis (found at $m / z 503.1524$ for $[\mathrm{M}+\mathrm{H}]^{+}$, calcd. 503.1553) requiring thirteen degrees of unsaturation (Additional file 1: Figure S1). The $600 \mathrm{MHz}$ instrument for ${ }^{1} \mathrm{H},{ }^{13} \mathrm{C}$, COSY, HSQC and HMBC (optimized for $J=8.3 \mathrm{~Hz}$ and $J=4.0 \mathrm{~Hz}$ ) in DMSO- $\mathrm{d}_{6}$ was used for processing the NMR spectral analyses. Initial investigation of NMR spectral data of $\mathbf{1}$ (Table 2) exhibited characteristic signals for a C-4 substituted ( $R$ )-fridamycin E moiety (Krohn and Baltus 1988; Myronovskyi et al. 2016; Vicente et al. 2015).

The aromatic region in ${ }^{1} \mathrm{H}$ NMR spectrum (Additional file 1: Figure S2) displayed the presence of two different aromatic spin systems of ortho-coupled protons; one corresponds to a tri-substituted benzene ring consisting of two one-proton doublets at $\delta_{\mathrm{H}} 7.95(J=7.8 \mathrm{~Hz})$ and $7.70(J=8.4 \mathrm{~Hz})$ assignable to $\mathrm{H}-1$ and $\mathrm{H}-3$, respectively, in addition to a one proton doublet of doublet at $\delta_{\mathrm{H}} 7.86(\mathrm{~J}=7.8$ and $8.4 \mathrm{~Hz})$, of $\mathrm{H}-2$. Another spin system consists of two one-proton doublets at $\delta_{\mathrm{H}} 7.78$ $(J=7.8 \mathrm{~Hz})$ and $7.61(J=7.8 \mathrm{~Hz})$ assignable to protons $\mathrm{H}-6$ and H-7, respectively, of the tetra-substituted aromatic system. Moreover, the ${ }^{1} \mathrm{H}$ NMR spectrum showed two one-proton doublets at $\delta_{\mathrm{H}} 2.88(\mathrm{~J}=13.2 \mathrm{~Hz})$ and 3.03 $(J=13.2 \mathrm{~Hz})$, attributed to the two geminally coupled protons, characteristic for $\mathrm{H}-11 \mathrm{a}$ and $\mathrm{H}-11 \mathrm{~b}$, respectively.

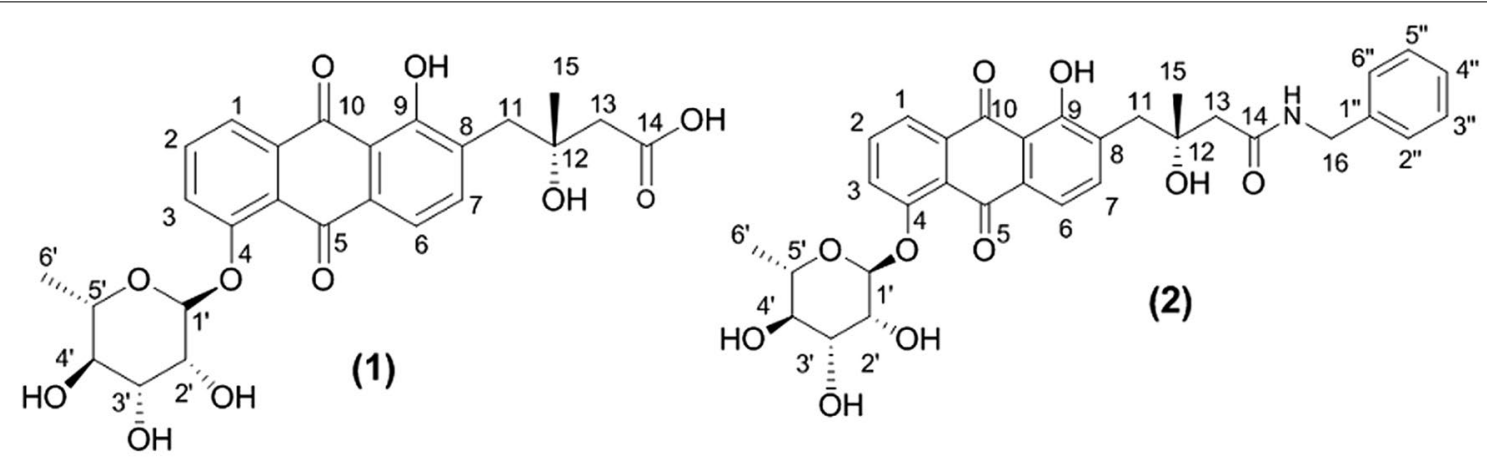

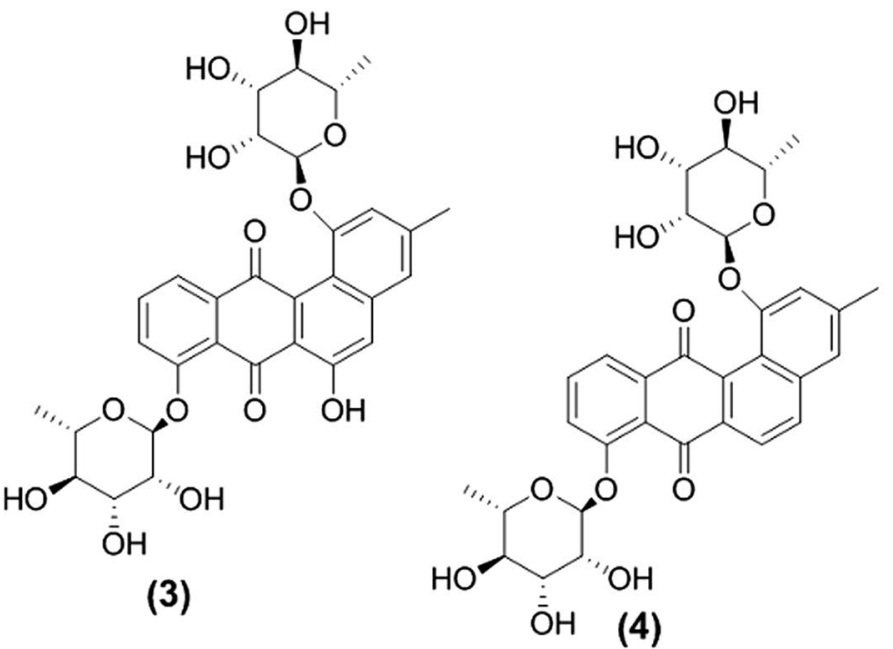<smiles>Cc1cc(O)c2c3c(ccc2c1)C(=O)c1c(OC2O[C@H](C)[C@@H](O)[C@H](O)[C@H]2O)cccc1C3=O</smiles>

(5)

Fig. 3 Structures of the isolated compounds: fridamycin $H(\mathbf{1})$ and I (2), actinosprin C (3), D (4) and G (5) 
Table $2{ }^{1} \mathrm{H}$ and ${ }^{13} \mathrm{C}$ NMR data (DMSO-d $\mathrm{d}_{6}, 600$ and $150 \mathrm{MHz}$ ) of 1

\begin{tabular}{|c|c|c|c|c|}
\hline Position & $\delta_{\mathrm{H}}$, mult $(J$ in $\mathrm{Hz})$ & $\delta_{C}$, type & COSY & HMBC \\
\hline 1 & $7.95, d(7.8)$ & 120.6, CH & $\mathrm{H}-2$ & $C-3,10$ \\
\hline 2 & $7.86, \mathrm{dd}(7.8,8.4)$ & $135.4, \mathrm{CH}$ & $\mathrm{H}-1,3$ & $C-4,10 a$ \\
\hline 3 & $7.70, d(8.4)$ & 123.6, CH & $\mathrm{H}-2$ & $C-1,4 a$ \\
\hline 4 & - & $156.8, C$ & - & - \\
\hline $4 a$ & - & $122.3, \mathrm{C}$ & - & - \\
\hline 5 & - & 181.2, C & - & - \\
\hline $5 a$ & - & 133.4, C & - & - \\
\hline 6 & $7.61, d(7.8)$ & $118.2, \mathrm{CH}$ & $\mathrm{H}-7$ & $C-8,9 a, 5$ \\
\hline 7 & $7.78, d(7.8)$ & 141.0, CH & $\mathrm{H}-6$ & $C-5 a, 9$ \\
\hline 8 & - & 133.4, C & - & - \\
\hline 9 & - & $160.3, C$ & - & - \\
\hline $9 a$ & - & 115.1, C & - & - \\
\hline 10 & - & 188.9, C & - & - \\
\hline $10 a$ & - & $135.2, \mathrm{C}$ & - & - \\
\hline $\begin{array}{l}11 a \\
11 b\end{array}$ & $\begin{array}{l}\text { 2.88, d (13.2) } \\
\text { 3.03, d (13.2) }\end{array}$ & $40.1, \mathrm{CH}_{2}$ & - & $C-7,9$ \\
\hline 12 & - & $71.5, \mathrm{C}$ & - & - \\
\hline 13 & $2.40, \mathrm{~s}$ & 46.7, $\mathrm{CH}_{2}$ & - & $C-11$ \\
\hline 14 & - & $172.8, C$ & - & - \\
\hline 15 & $1.19, \mathrm{~s}$ & $26.8, \mathrm{CH}_{3}$ & - & $C-11,13$ \\
\hline $1^{\prime}$ & $5.64, d(1.8)$ & $99.3, \mathrm{CH}$ & $\mathrm{H}-2^{\prime}$ & $C-4^{\prime}, 5^{\prime}$ \\
\hline $2^{\prime}$ & $3.99, \mathrm{~m}$ & $70.5, \mathrm{CH}$ & $\mathrm{H}-1^{\prime}$ & $C-1^{\prime}$ \\
\hline $3^{\prime}$ & $3.99, \mathrm{~m}$ & $70.5, \mathrm{CH}$ & $\mathrm{H}-4^{\prime}$ & - \\
\hline $4^{\prime}$ & $3.33, \mathrm{~m}$ & $72.0, \mathrm{CH}$ & $\mathrm{H}-3^{\prime}$ & - \\
\hline $5^{\prime}$ & $3.52, \mathrm{~m}$ & $70.4, \mathrm{CH}$ & $\mathrm{H}-4^{\prime}, 6^{\prime}$ & - \\
\hline $6^{\prime}$ & $1.09, d(6)$ & $18.4, \mathrm{CH}_{3}$ & $\mathrm{H}-5^{\prime}$ & $C-5^{\prime}, 4^{\prime}$ \\
\hline
\end{tabular}

Whereas, the two-protons singlet at $\delta_{\mathrm{H}} 2.40$ was assignable for $\mathrm{H}-13$, belonging to the protons of a methylene group directly linked to the carboxyl group. One singlet at $\delta_{\mathrm{H}} 1.19$ together with its corresponding carbon signal at $\delta_{\mathrm{C}} 26.8$ was for the methyl group $\left(\mathrm{CH}_{3}-15\right)$ which was considerably downfield shifted due to its direct attachment to oxygenated carbon at $\delta_{\mathrm{C}} 71.5(\mathrm{C}-12)$ (Vicente et al. 2015). Moreover, the presence of an anomeric proton signal at $\delta_{\mathrm{H}} 5.64(J=1.8 \mathrm{~Hz} ; \delta \mathrm{C} 99.3)$, one methyl doublet at $\delta_{\mathrm{H}} 1.09(\mathrm{~J}=6 \mathrm{~Hz})$, as well as four one-proton multiplets at $\delta_{\mathrm{H}}(3.33-3.99)$ indicated the presence of the rhamnose moiety in the structure (Grkovic et al. 2014). The coupling constant of the anomeric proton allowed the identification of an $\alpha$ anomer and the absolute configuration of sugar was determined to be $L$ based on the literature (Dashti et al. 2017).

The ${ }^{13} \mathrm{C}$ NMR and HSQC spectra (Additional file 1: Figures S3, S5) displayed fourteen resonances comprising five methine $\mathrm{sp}^{2}$, five methine $\mathrm{sp}^{3}$, two methylene $\mathrm{sp}^{3}$, two methyl carbons consistent with an angucycline core and one glycosidic residue. Three carbonyl carbons were displayed, the upfield shifted carbon at $\delta_{\mathrm{C}} 172.8$ was attributed to free carboxyl group (C-14), while the others resonated at $\delta_{C} 181.2$ and 188.9 were assigned to quinone carbonyl carbons $\mathrm{C}-5$ and $\mathrm{C}-10$, respectively. Additionally two methylene carbons $\mathrm{C}-11$ and $\mathrm{C}-13$ were observed; the latter was deshielded to $46.7 \mathrm{ppm}$ in agreement with direct attachment to carboxylic group, while the former one was detected at $40.1 \mathrm{ppm}$ due to its direct attachment to the aromatic ring that could be confirmed by $\mathrm{HMBC}$ correlations from $\mathrm{H}-11 \mathrm{a}$ and $\mathrm{H}-11 \mathrm{~b}\left(\delta_{\mathrm{H}} 2.88\right.$ and 3.03) to $C-7\left(\delta_{C} 141.0\right)$ and $C-9\left(\delta_{C} 160.3\right)$. Two oxygenated aromatic carbons were observed at $\delta_{C} 156.8$ and 160.3 , assignable to $C-4$ and $C-9$, respectively. The former (C-4) displayed HMBC correlation to the anomeric proton of L-rhamnose $\left(\delta_{\mathrm{H}} 5.64, \mathrm{H}-1^{\prime}\right)$, confirming the attachment of L-rhamnose to $\mathrm{C}-4$ of the anthraquinone motif (Fig. 4). Due to a small amount of $\mathbf{1}$ obtained in this study, it was not possible to determine the absolute configuration of $\mathrm{C}-12$. However, as $\mathbf{1}$ is a 4-O-glycosylated fridamycin $\mathrm{E}$, we speculated that the absolute configuration of $\mathrm{C}-12$ of 1 should be the same as that of naturally occurring fridamycin $\mathrm{E}$ (Krohn and Baltus 1988) i.e. $12 \mathrm{R}$. However, it is necessary to obtain more amount of 1 to determine conclusively the absolute configuration of C-12. As a common biosynthesis feature of Streptomyces sp., all the naturally identified fridamycin $\mathrm{E}$ analogues retain the $(\mathrm{R})$ configuration $\left(\alpha-\mathrm{OH}\right.$ and $\left.\beta-\mathrm{CH}_{3}\right)$ at $\mathrm{C}-12$. Whereas the (S) isomers, $\left(\alpha-\mathrm{CH}_{3}\right.$ and $\left.\beta-\mathrm{OH}\right)$ at $\mathrm{C}-12$, have been only obtained chemosynthetically as the less bioactive isomers of fridamycin $\mathrm{E}$ analogues (Bruntner et al. 2005; Chen et al. 2011; Rohr and Thiericke 1992; Vicente et al. 2015).

COSY, HSQC and HMBC experiments (Additional file 1: Figures S4-S6) were used to support the aforementioned assignments and the structure of $\mathbf{1}$, which was a new compound that we named fridamycin $\mathrm{H}$.

HR-ESIMS of 2 (Fig. 3) established the molecular formula as $\mathrm{C}_{32} \mathrm{H}_{33} \mathrm{NO}_{10} \mathrm{Na}$ (found at $\mathrm{m} / z$ 614.2036, calcd. 614.2021) $[\mathrm{M}+\mathrm{Na}]^{+}$) requiring seventeen degrees of unsaturation Additional file 1: Figure S7). First investigation of the NMR spectroscopic data of 2 (Table 3) (Additional file 1: Figures S8-S12) showed many signals similar to chemical shifts of those reported for $\mathbf{1}$ (fridamycin $\mathrm{H}$ ) except for the substitution of the carboxyl group of $\mathbf{1}$ with $N$-benzyl amide moiety that was represented by multiplet signals at $\delta_{\mathrm{H}} 7.25,7.30$ and 7.24 assignable to $\left(\mathrm{H}-2^{\prime \prime}, 6^{\prime \prime}\right),\left(\mathrm{H}-3^{\prime \prime}\right.$, $\left.5^{\prime \prime}\right)$ and $\mathrm{H}-4^{\prime \prime}$, respectively, in accordance with monosubstituted benzene ring. Two-protons singlet at $\delta_{\mathrm{H}}$ 3.54 along with its corresponding carbon signal at $\delta_{\mathrm{C}}$ 40.9 were for the methylene group $\left(\mathrm{CH}_{2}-16\right)$ directly attached to the benzene ring and one singlet at $\delta_{\mathrm{H}}$ 8.17 corresponding to an amine proton (Myronovskyi 


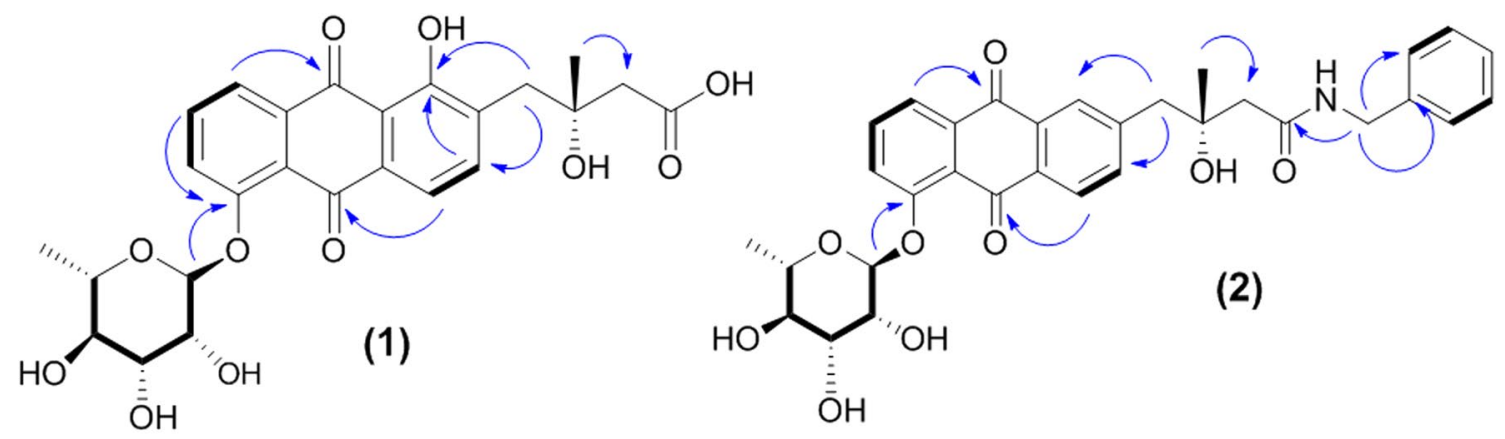

$1 \mathrm{H}-1 \mathrm{H}$ COSY

HBMC

Fig. 4 Key COSY and HMBC correlations of fridamycin $\mathrm{H}$ (1) and I (2)

et al. 2016). Moreover, HMBC correlations from $\mathrm{H}-16$ $\left(\delta_{\mathrm{H}} 3.54\right)$ to $\mathrm{C}-1^{\prime \prime}$ and $\mathrm{C}-2^{\prime \prime}, 6^{\prime \prime}$ at $\delta_{\mathrm{C}} 135.45$ and 129.7, respectively and to amide-type carbonyl carbon at $\left(\delta_{\mathrm{C}}\right.$ 173.2) were observed confirming direct attachment of the methylene group $\left(\mathrm{CH}_{2}-16\right)$ to the benzene ring from one side and to the amide moiety from the other side (Myronovskyi et al. 2016) (Fig. 4).

COSY, HSQC and HMBC experiments (Additional file 1: Figures S10-S12) were used to support the aforementioned assignments and the structure of compound 2, which was a new compound that we named fridamycin I.

Separation of fraction 5 delivered three actinosporins with similar UV spectra (250, 270, and $320 \mathrm{~nm})$. By comparing their spectra (Additional file 1: Figures S13-S21) with previously published data (Dashti et al. 2017; Grkovic et al. 2014), the structures of these compounds were confirmed as actinosporin C (3), D (4) and G (5).

\section{Biological activity of the isolated compounds}

All the isolated compounds were tested against Trypanosoma brucei strain TC221 (Abdelmohsen et al. 2014b; Huber and Koella 1993). Compound 1 showed significant antitrypanosomal activity after 48 and $72 \mathrm{~h}$ with $\mathrm{IC}_{50}$ values of 7.18 and $3.35 \mu \mathrm{M}$, respectively, with no cytotoxicity against J774.1 macrophages $\left(\mathrm{IC}_{50}\right.$ of $>200 \mu \mathrm{M})$. While the rest displayed no significant antitypanosomal or cytotoxic activity at the concentration tested.

\section{Discussion}

Bioinformatic analyses have revealed the presence of large fractions of silent gene clusters in the genome sequences of actinomycetes. Innovative strategies had been used to induce production of weakly expressed secondary metabolites which are not expressed under standard fermentation conditions and several approaches including biological, chemical, and molecular, have been applied to activate those silent natural products in the laboratory culture of actinomycetes (Abdelmohsen et al. 2015). Among those approaches, OSMAC approach (one strain many compounds), co-cultivation and applying of external chemical elicitors (Romano et al. 2018). In our previous studies the genome sequences (Harjes et al. 2014) as well as metabolomic analyses (Abdelmohsen et al. 2014b) of Actinokineospora spheciospongiae sp. nov. showed unexplored chemical potential. Actinosporins A and B had been isolated using broth culture of Actinokineospora sp. strain EG49 (Abdelmohsen et al. 2014b), while supplementing the same culture with calcium alginate beads allowed identification of actinosporins $C$ and D have been identified (Grkovic et al. 2014). Moreover, induction of liquid culture of Actinokineospora sp. EG49 with GlcNAc has resulted in the isolation of and characterization of actinosporins E-H (Dashti et al. 2017). In the current approach, elicitation of the solid culture of Actinokineospora spheciospongiae sp. nov. via GlcNAc resulted in isolation and characterization of two new fridamycins $\mathrm{H}(\mathbf{1})$ and I (2), along with three known actinosporins C (3), D (4) and G (5).

On the other side, trypanosomiasis, commonly known as sleeping sickness, still has been considered one of the most serious challenges to human health, particularly in underdeveloped regions of Africa (Jacobs et al. 2011; Malvy and Chappuis 2011). It is commonly combined with degradation of hepatic cells, anemia and glomerulonephritis which are likely ascribed to considerable free radicals produced by the parasites which attack cellular membrane, leading to 
Table $3{ }^{1} \mathrm{H}$ and ${ }^{13} \mathrm{C}$ NMR data (DMSO-d $\mathrm{d}_{6}, 600$ and $150 \mathrm{MHz}$ ) of 2

\begin{tabular}{|c|c|c|c|c|}
\hline Position & $\delta_{H}$, mult $(J$ in $\mathrm{Hz})$ & $\delta_{c}$, type & $\cos Y$ & HMBC \\
\hline 1 & $7.95, d(7.8)$ & 120.6, CH & $\mathrm{H}-2$ & $C-3,4 a, 10$ \\
\hline 2 & $7.85, \mathrm{dd}(7.8,8.4)$ & $135.5, \mathrm{CH}$ & $\mathrm{H}-1,3$ & $C-4,10 a$ \\
\hline 3 & $7.70, d(8.4)$ & $123.8, \mathrm{CH}$ & $\mathrm{H}-2$ & $C-1,4 a$ \\
\hline 4 & - & $156.7, C$ & - & - \\
\hline $4 a$ & - & 122.1, C & - & - \\
\hline 5 & - & $180.8, \mathrm{C}$ & - & - \\
\hline $5 a$ & - & 133.35, C & - & - \\
\hline 6 & $7.61, d(7.8)$ & 118.3, CH & $\mathrm{H}-7$ & $C-8,9 a, 5$ \\
\hline 7 & $7.79, d(7.8)$ & 140.3, CH & $\mathrm{H}-6$ & C5a, 9, 11 \\
\hline 8 & - & $133.2, \mathrm{C}$ & - & - \\
\hline 9 & - & $160.3, \mathrm{C}$ & - & - \\
\hline $9 a$ & - & $115.1, C$ & - & - \\
\hline 10 & - & 189.0, C & - & - \\
\hline $10 a$ & - & $135.3, \mathrm{C}$ & - & - \\
\hline $\begin{array}{l}11 a \\
11 b\end{array}$ & $\begin{array}{l}2.88, d(13.2) \\
3.03, d(13.2)\end{array}$ & $39.9, \mathrm{CH}$ & - & $C-7,9,13,15$ \\
\hline 12 & - & $71.4, \mathrm{C}$ & - & - \\
\hline 13 & $2.39, \mathrm{~s}$ & 46.6, $\mathrm{CH}_{2}$ & - & $C-11,15$ \\
\hline 14 & - & $173.2, \mathrm{C}$ & - & - \\
\hline 15 & $1.18, \mathrm{~s}$ & $26.5, \mathrm{CH}_{3}$ & - & $C-11,13$ \\
\hline 16 & $3.54, \mathrm{~s}$ & $40.9, \mathrm{CH}_{2}$ & - & $C-14,1^{\prime \prime}, 2^{\prime \prime}, 6^{\prime \prime}$ \\
\hline $1^{\prime}$ & $5.64, d(1.8)$ & 99.0, $\mathrm{CH}$ & $\mathrm{H}-2^{\prime}$ & $C-4,5^{\prime \prime}$ \\
\hline $2^{\prime}$ & $3.99, \mathrm{~m}$ & $70.4, \mathrm{CH}$ & $\mathrm{H}-1^{\prime}$ & $C-1^{\prime \prime}$ \\
\hline $3^{\prime}$ & $3.99, \mathrm{~m}$ & $70.5, \mathrm{CH}$ & $\mathrm{H}-4^{\prime}$ & - \\
\hline $4^{\prime}$ & $3.33, \mathrm{~m}$ & 72.0, $\mathrm{CH}$ & $\mathrm{H}-3^{\prime}$ & - \\
\hline $5^{\prime}$ & $3.52 \mathrm{~m}$ & 70.6, CH & $\mathrm{H}-4^{\prime}, 6^{\prime}$ & - \\
\hline $6^{\prime}$ & $1.08, d(6)$ & $18.2, \mathrm{CH}_{3}$ & $\mathrm{H}-5^{\prime}$ & $C-5^{\prime \prime}, 4^{\prime \prime}$ \\
\hline $1^{\prime \prime}$ & - & $135.5, \mathrm{C}$ & - & - \\
\hline $2^{\prime \prime}, 6^{\prime \prime}$ & $7.25, \mathrm{~m}$ & 129.7, CH & $\mathrm{H}-3^{\prime \prime}, 5^{\prime \prime}$ & - \\
\hline $3^{\prime \prime}, 5^{\prime \prime}$ & $7.30, m$ & 128.7, CH & $\mathrm{H}-2^{\prime \prime}, 6^{\prime \prime}$ & - \\
\hline $4^{\prime \prime}$ & $7.24 \mathrm{~m}$ & $127.0, \mathrm{CH}$ & - & - \\
\hline $14-\mathrm{NH}$ & 8.17 br s & - & - & - \\
\hline
\end{tabular}

cellular damages of human vital organs. So far, effective antitrypanosomally drugs are still not accessible, regardless the extensive efforts to achieve treatments (Ibrahim et al. 2013; Steverding 2010). Thus, ongoing research for new classes of metabolites with antitrypanosomal activity is necessary. Consequently, two new fridamycins $\mathrm{H}(\mathbf{1})$ and I (2), along with three known actinosporins C (3), D (4) and G (5) were considered for the examination of the antitrypanosomal property versus Trypanosoma brucei TC221 in addition to cytototoxic properties towards Macrophages (J774.1). The results obtained displayed that fridamycin $\mathrm{H}$ showed significant antitrypanosomal activity after 48 and $72 \mathrm{~h}$ with $\mathrm{IC}_{50}$ values of 3.38 and $5.26 \mu \mathrm{M}$, respectively, with no cytotoxicity against J774.1 macrophages
$\left(\mathrm{IC}_{50}>200 \mu \mathrm{M}\right)$. These results demonstrate the potential of elicitation via compound induction as a tool for discovery of new antitrypanosomal chemical scaffolds.

\section{Additional file}

Additional file 1. Additional figures.

\section{Authors' contributions}

Conceptualization, URA; Formal analysis, AT, RE-E and URA; Investigation, AT, EZA, SYD, DH and AAM; Supervision, RE-E and URA; Writing-original draft, AT, EZA and SYD; Writing-review and editing, PJS, RE-E and URA. All authors read and approved the final manuscript.

\section{Author details}

${ }^{1}$ Computational and Analytical Science Department, Rothamsted Research, AL5 2JQ Harpenden, UK. ${ }^{2}$ Department of Pharmacognosy, Faculty of Pharmacy, Helwan University, Cairo 11795, Egypt. ${ }^{3}$ Department of Pharmacognosy, Faculty of Pharmacy, Minia University, Minia 61519, Egypt. ${ }^{4}$ Department of Biochemistry, Faculty of Science, Center for Science and Medical Research, University of Jeddah, 80203 Jeddah, Saudi Arabia. ${ }^{5}$ Carl-von-Ossietzky University Oldenburg, Institute for Chemistry and Biology of the Marine Environment, Postfach 2503, 26111 Oldenburg, Germany.

\section{Acknowledgements}

We thank Vera Thoss for laboratory support and A. Stisch for antitrypanosomal activity testing.

\section{Competing interests}

The authors declare that they have no competing interests.

\section{Availability of data and materials}

All data generated or analyzed during this study are included in this published article.

\section{Consent for publication}

Not applicable.

Ethics approval and consent to participate

Not applicable.

Funding

This research received no external funding.

\section{Publisher's Note}

Springer Nature remains neutral with regard to jurisdictional claims in published maps and institutional affiliations.

Received: 21 December 2018 Accepted: 31 December 2018 Published online: 24 January 2019

\section{References}

Abdelmohsen UR, Pimentel-Elardo SM, Hanora A, Radwan M, Abou-El-Ela SH Ahmed S, Hentschel U (2010) Isolation, phylogenetic analysis and antiinfective activity screening of marine sponge-associated actinomycetes. Mar Drugs 8(3):399-412. https://doi.org/10.3390/md8030399

Abdelmohsen UR, Bayer K, Hentschel U (2014a) Diversity, abundance and natural products of marine sponge-associated actinomycetes. Nat Prod Rep 31(3):381-399. https://doi.org/10.1039/c3np70111e

Abdelmohsen UR, Cheng C, Viegelmann C, Zhang T, Grkovic T, Ahmed S, Quinn RJ, Hentschel U, Edrada-Ebel R (2014b) Dereplication strategies for targeted isolation of new antitrypanosomal actinosporins $A$ and $B$ 
from a marine sponge associated-Actinokineospora sp. EG49. Mar Drugs 12(3):1220-1244. https://doi.org/10.3390/md12031220

Abdelmohsen UR, Yang C, Horn H, Hajjar D, Ravasi T, Hentschel U (2014c) Actinomycetes from Red Sea sponges: sources for chemical and phylogenetic diversity. Mar Drugs 12(5):2771-2789. https://doi.org/10.3390/ md12052771

Abdelmohsen UR, Grkovic T, Balasubramanian S, Kamel MS, Quinn RJ, Hentschel U (2015) Elicitation of secondary metabolism in actinomycetes. Biotechnol Adv 33(6 Pt 1):798-811. https://doi.org/10.1016/j.biotechadv .2015 .06 .003

Abdelmohsen UR, Balasubramanian S, Oelschlaeger TA, Grkovic T, Pham NB, Quinn RJ, Hentschel U (2017) Potential of marine natural products against drug-resistant fungal, viral, and parasitic infections. Lancet Infect Dis 17(2):e30-e41. https://doi.org/10.1016/S1473-3099(16)30323-1

Abe N, Enoki N, Nakakita Y, Uchida H, Nakamura T, Munekata M (1993) Novel antitumor antibiotics, saptomycins. II. Isolation, physico-chemical properties and structure elucidation. J Antibiot (Tokyo) 46(10):1536-1549

Balasubramanian S, Othman EM, Kampik D, Stopper H, Hentschel U, Ziebuhr W, Oelschlaeger TA, Abdelmohsen UR (2017) Marine sponge-derived Streptomyces sp. SBT343 extract inhibits staphylococcal biofilm formation. Front Microbiol 8:236. https://doi.org/10.3389/fmicb.2017.00236

Bruntner C, Binder T, Pathom-aree W, Goodfellow M, Bull AT, Potterat O, Puder C, Horer S, Schmid A, Bolek W, Wagner K, Mihm G, Fiedler HP (2005) Frigocyclinone, a novel angucyclinone antibiotic produced by a Streptomyces griseus strain from antarctica. J Antibiot (Tokyo) 58(5):346-349. https:// doi.org/10.1038/ja.2005.43

Chen Q, Mulzer M, Shi P, Beuning PJ, Coates GW, O'Doherty GA (2011) De novo asymmetric synthesis of fridamycin E. Org Lett 13(24):6592-6595. https:// doi.org/10.1021/ol203041b

Cheng C, Maclntyre L, Abdelmohsen UR, Horn H, Polymenakou PN, EdradaEbel R, Hentschel U (2015) Biodiversity, anti-trypanosomal activity screening, and metabolomic profiling of actinomycetes isolated from mediterranean sponges. PLoS ONE 10(9):e0138528. https://doi.org/10.1371/journ al.pone.0138528

Cheng C, Balasubramanian S, Fekete A, Krischke M, Mueller MJ, Hentschel U, Oelschlaeger TA, Abdelmohsen UR (2017) Inhibitory potential of strepthonium A against Shiga toxin production in enterohemorrhagic Escherichia coli (EHEC) strain EDL933. Nat Prod Res 31(23):2818-2823. https://doi.org/10.1080/14786419.2017.1297443

Dashti Y, Grkovic T, Abdelmohsen UR, Hentschel U, Quinn RJ (2017) Actinomycete metabolome induction/suppression with $\mathrm{N}$-acetylglucosamine. J Nat Prod 80(4):828-836. https://doi.org/10.1021/acs.jnatprod.6b00673

Dinesh R, Srinivasan V, Anandaraj M, Srambikkal H (2017) Endophytic actinobacteria: diversity, secondary metabolism and mechanisms to unsilence biosynthetic gene clusters. Crit Rev Microbiol 43(5):546-566. https://doi. org/10.1080/1040841X.2016.1270895

Genilloud O (2017) Actinomycetes: still a source of novel antibiotics. Nat Prod Rep 34(10):1203-1232. https://doi.org/10.1039/c7np00026j

Geraci C, Neri P, Paterno C, Rocco C, Tringali C (2000) An unusual nitrogenous terphenyl derivative from fruiting bodies of the basidiomycete Sarcodon leucopus. J Nat Prod 63(3):347-351

Grkovic T, Abdelmohsen UR, Othman EM, Stopper H, Edrada-Ebel R, Hentschel U, Quinn RJ (2014) Two new antioxidant actinosporin analogues from the calcium alginate beads culture of sponge-associated Actinokineospora sp. strain EG49. Bioorg Med Chem Lett 24(21):5089-5092. https://doi. org/10.1016/j.bmcl.2014.08.068

Harjes J, Ryu T, Abdelmohsen UR, Moitinho-Silva L, Horn H, Ravasi T, Hentschel U (2014) Draft genome sequence of the antitrypanosomally active sponge-associated bacterium Actinokineospora sp. strain EG49. Genome Announc. https://doi.org/10.1128/genomea.00160-14

Horn H, Cheng C, Edrada-Ebel R, Hentschel U, Abdelmohsen UR (2015) Draft genome sequences of three chemically rich actinomycetes isolated from Mediterranean sponges. Mar Genomics 24(Pt 3):285-287. https://doi. org/10.1016/j.margen.2015.10.003
Huber W, Koella JC (1993) A comparison of three methods of estimating EC50 in studies of drug resistance of malaria parasites. Acta Trop 55(4):257-261 Ibrahim MA, Aliyu AB, Abdullahi H, Solomon T, Toko E, Garba A, Bashir M, Habila N (2013) Lactone-rich fraction from Vernonia blumeoides: antitrypanosomal activity and alleviation of the parasite-induced anemia and organ damage. J Nat Med 67(4):750-757. https://doi.org/10.1007/s1141 8-012-0737-9

Ibrahim AH, Attia EZ, Hajjar D, Anany MA, Desoukey SY, Fouad MA, Kamel MS, Wajant H, Gulder TAM, Abdelmohsen UR (2018) New cytotoxic cyclic peptide from the marine sponge-associated Nocardiopsis sp. UR67. Mar Drugs 16:9. https://doi.org/10.3390/md16090290

Jacobs RT, Nare B, Phillips MA (2011) State of the art in African trypanosome drug discovery. Curr Top Med Chem 11(10):1255-1274

Kampfer P, Glaeser SP, Busse HJ, Abdelmohsen UR, Ahmed S, Hentschel U (2015) Actinokineospora spheciospongiae sp. nov., isolated from the marine sponge Spheciospongia vagabunda. Int I Syst Evol Microbiol 65(Pt 3):879-884. https://doi.org/10.1099/ijs.0.000031

Krohn K, Baltus W (1988) Synthesis of rac- and ent-Fridamycin E. Tetrahedron 44:49

Kunzel E, Faust B, Oelkers C, Weissbach U, Bearden DW, Weitnauer G, Westrich L, Bechthold A, Rohr J (1999) Inactivation of the urdGT2 gene, which encodes a glycosyltransferase responsible for the C-glycosyltransfer of activated D-olivose, leads to formation of the novel urdamycins I, J, and K. J Am Chem Soc 121:11058-11062

Letzel AC, Li J, Amos GCA, Millan-Aguinaga N, Ginigini J, Abdelmohsen UR, Gaudencio SP, Ziemert N, Moore BS, Jensen PR (2017) Genomic insights into specialized metabolism in the marine actinomycete Salinispora. Environ Microbiol 19(9):3660-3673. https://doi.org/10.1111/1462-2920.13867

Malvy D, Chappuis F (2011) Sleeping sickness. Clin Microbiol Infect 17(7):986995. https://doi.org/10.1111/j.1469-0691.2011.03536.x

Myronovskyi M, Brotz E, Rosenkranzer B, Manderscheid N, Tokovenko B, Rebets Y, Luzhetskyy A (2016) Generation of new compounds through unbalanced transcription of landomycin A cluster. Appl Microbiol Biotechnol 100(21):9175-9186. https://doi.org/10.1007/s00253-016-7721-3

Nancy NG, Mary PL (1984) Novel benzo[a]naphthacene quinones from an actinomycete, Frankia G-2 (ORS 020604). Can J Chem 62(12):2818-2821

Pettit RK (2011) Small-molecule elicitation of microbial secondary metabolites. Microb Biotechnol 4(4):471-478. https://doi.org/10.111 1/j.1751-7915.2010.00196.x

Rohr J, Thiericke R (1992) Angucycline group antibiotics. Nat Prod Rep 9(2):103-137

Romano S, Jackson SA, Patry S, Dobson ADW (2018) Extending the "One Strain Many Compounds" (OSMAC) principle to marine microorganisms. Mar Drugs. https://doi.org/10.3390/md16070244

Seyedsayamdost MR (2014) High-throughput platform for the discovery of elicitors of silent bacterial gene clusters. Proc Natl Acad Sci USA 111(20):7266-7271. https://doi.org/10.1073/pnas.1400019111

Steverding D (2010) The development of drugs for treatment of sleeping sickness: a historical review. Parasit Vectors 3(1):15. https://doi. org/10.1186/1756-3305-3-15

Tawfike AF, Tate R, Abbott G, Young L, Viegelmann C, Schumacher M, Diederich M, Edrada-Ebel R (2017) Metabolomic tools to assess the chemistry and bioactivity of endophytic Aspergillus strain. Chem Biodivers. https://doi. org/10.1002/cbdv.201700040

Van der Meij A, Worsley SF, Hutchings MI, van Wezel GP (2017) Chemical ecology of antibiotic production by actinomycetes. FEMS Microbiol Rev 41(3):392-416

Vicente J, Stewart AK, van Wagoner RM, Elliott E, Bourdelais AJ, Wright JL (2015) Monacyclinones, new angucyclinone metabolites isolated from Streptomyces sp. M7_15 associated with the puerto rican sponge Scopalina ruetzleri. Mar Drugs 13(8):4682-4700. https://doi.org/10.3390/ md13084682 